\title{
Survival outcomes of lobectomy in comparison with segmentectomy in clinical stage I non-small-cell lung cancer: a meta-analysis
}

\author{
Jian Feng \\ Funing People's Hospital \\ Yan-Yue Han \\ Funing People's Hospital \\ Yue Wang \\ Funing People's Hospital \\ Xiu-Yu Wu \\ Funing People's Hospital \\ Feng Lv \\ Funing People's Hospital \\ Yang Liu \\ Funing People's Hospital \\ Bing-Hui Chen ( $\nabla$ dnesg6@163.com ) \\ Funing People's Hospital https://orcid.org/0000-0002-8188-1326
}

\section{Research article}

Keywords: NSCLC; lobectomy; segmentectomy; meta-analysis

Posted Date: September 7th, 2019

DOI: https://doi.org/10.21203/rs.2.14067/v1

License: (c) (i) This work is licensed under a Creative Commons Attribution 4.0 International License. Read Full License 


\section{Abstract}

Background: The gold standard surgical therapy for patients with Clinical stage I non-small-cell lung cancer (NSCLC) is lobectomy with mediastinal lymph node dissection. While, segmentectomy has emerged as an alternative choice with the advantage of fewer postoperative complications. While the acceptance of this procedure still remains controversial, and conflicting results exist in the retrospective trials.

Objectives: The aim of this meta-analysis was to analysis the survival outcomes of Lobectomy in comparison with segmentectomy in treatment of Clinical stage I non-small-cell lung cancer. Methods: Computerized literature search was done on the published trials in Pubmed, Embase, Cochrane library databases to June, 2019 to identify clinical trials. Lung cancer-specific survival (LCSS) and overall survival (OS) were measured as outcomes. Statistical analysis was performed in the Meta-analysis Revman 5.3 software.

Results: A systematic literature search was conducted including 7 studies. In this meta-analysis, results indicate that lobectomy confers an equivalent survival outcome compared with segmentectomy.

Conclusion: No significant differences were found in survival outcomes between lobectomy and segmentectomy. Further prospective large-scale, prospective, randomized trials are needed to explore the reasonable surgical treatment for early resectable lung cancer.

\section{Background}

Wide-ranging use of low-dose spiral computed tomography (LDCT) and high-resolution computed tomography (HRCT) makes it possible to detect early non-small cell lung cancer (NSCLC) (1). Surgical resection has been accepted as the mainstay therapy for early-stage NSCLC (2).

A randomized controlled trial of the Lung Cancer Study Group showed that lobectomy is the preferred method for clinical stage I NSCLC (3). Although lobectomy along with mediastinal lymph node dissection remains the mainstay of care, some studies have reported the conflicting evidences regarding to the extent of parenchymal resection required for local control of the tumor and disease-free survival (4-5).

Recently, previous reports have shownsimilar survival with sublobar resection and lobectomy for early-stage NSCLC (69). Segmentectomy, as one of the limited resection surgical options, was first reported by Jensik et al (10). A large propensity-matched study demonstrated that compared with lobectomy, patients who underwent anatomic segmentectomy should be accepted as more reasonable and justifiable option than lobectomy in selected cases as the perioperative and oncologic results achieved with less lung tissue and better pre- served pulmonary function (2). Although anatomical segmentectomy have been introduced as an appropriate alternative to lobectomy, controversy still exists due to the lack of randomized trials and patient selection bias in available trials (11).

To deal with the biases inherent in any non-randomized comparison, we analyzed the propensity-matched analysis and randomized clinical trial. The aim of our meta-analysis was to evaluate the survival outcomes between lobectomy and segmentectomy in treatment outcomes of stage I NSCLC patients.

\section{Methods}

\section{Search strategy}

Two investigators conducted a systematic search of the Pubmed, Embase, Cochrane library up to June 2019 independently, using the MeSH terms and free key words 'lobectomy' or 'segmentectomy' or 'early-stage' or 'stage I' or 
'non-small cell lung cancer' with 'propensity' or 'propensity score' or 'propensity match' or 'randomized clinical trial'. The reference lists of eligible studies were also hand-searched to check for additional studies.

\section{Eligibility criteria}

Inclusion criteria were articles relating to: (1) the studies are designed as randomized clinical trial or propensity score comparisons compare the lobectomy with segmentectomy; (2) articles that enrolled stage I NSCLC patients; (3) the outcomes of interest were lung cancer-specific survival (LCSS) and overall survival (OS); (4) the full-text literature were only included.

\section{Risk-of-Bias Assessments}

The risk of bias for each included study was systematically evaluated by Cochrane Collaboration based on the Cochrane Handbook version 5.1.0, independently assessed by two researchers.

\section{Data extraction}

The authors extracted the following information independently from each study and resolved the differences through discussion. A self-designed data extraction table is used to extract content independently: first author's last name, publication year, subject's demographic (subject number and age) and tumor size. The differences are based on consensus.

\section{Statistical analysis}

If the study does not provide data on $\mathrm{HR}$ or $95 \% \mathrm{Cl}$, and all available data are in the form of Kaplan-Meier (K-M) curves. Survival data were extracted from amplified K-M curves, according to the methods described by Tierney JF (12).

Heterogeneity in all studies was measured by the $\mathrm{I}^{2}$ statistic (13). If the heterogeneity assessment is not significant (I2 $\leq$ $50 \%$ ), a fixed effect model is used. If the source of heterogeneity is not significant (I2> 50\%) uncertain, we use a random effects model for further analysis (14). A P value of less than 0.05 was considered to be a statistically significant difference. Statistical analysis was performed in Review Manager version 5.3 software (Revman; The Cochrane collaboration Oxford, United Kingdom). The results of our meta-analysis are shown in forest plots.

\section{Results}

Study selection and Characteristics of study selection

A total of 357 studies were retrieved. Eleven publications were evaluated in more detail based on the criteria described in the method, but some publications did not provide sufficient detail on the results of the two methods. Finally, a total of seven trials $(2,4,15-19)$ evaluated survival outcomes compared to lobectomy and segmentectomy. The search process is depicted in Figure 1. Table 1 shows the main features of the eligible studies in more detail.

Clinical and methodological heterogeneity

Pooled analysis of LCSS comparing lobectomy versus segmentectomy

The pooled LCSS data did not gain an advantage between the two groups $(\mathrm{OR}=0.72,95 \% \mathrm{Cl}=0.41-1.26, \mathrm{P}=0.25)$. In other words, neither lobectomy nor segmentectomy has an LCSS advantage (Figure 2).

Pooled analysis of OS comparing lobectomy versus segmentectomy

Page $3 / 9$ 
The pooled results derived from the random-effects model are presented in figure 3 . The data showed that there was no benefit comparing lobectomy versus segmentectomy for stage I NSCLC (OR=0.86,95\% Cl=0.60-1.23, P=0.40) (Fig. 3).

\section{Discussion}

Pneumonectomy has been the main treatment for resectable lung cancer in the past 20 years (20-21). Since the introduction of lobectomy in the late 1950s, it has become the surgical treatment of choice for patients with early NSCLC, with reduced morbidity and mortality, and the observed long-term survival after 5 years (22).

Surgery should not only be completely removed, but also have a good quality of life. Surgical treatment of patients may not be common, as evidence suggests that elderly patients with early NSCLC or patients who are intolerant to lobectomy due to poor cardiopulmonary reserve and multiple comorbidities may be beneficial for segmentectomy (19).

In addition, the JCOG team has conducted several promising RCTs to test the effectiveness of segmentectomy to determine if segmentectomy can be a suitable alternative to early stage lung cancer (23-24).

This meta-analysis failed to report a better segmentectomy than lobectomy, and the results were similar between the two groups in terms of OS and LCSS.

To the best of our knowledge, some trials have reported that an in vitro physician's decision and/or patient-related factors may influence the choice of surgery. Preoperative clinical factors may have an impact on the decision to perform accurate mediastinal LN resection, such as clinical stage, patient age, and limited resection.

A study by Smith et al. (25) showed that, based on surveillance, epidemiology and final outcome (SEER) - Medicare registration, segmental resection should be an alternative treatment for limited resection of patients with stage NS NSCLC.

In the Veluswamy study, the study reported differences in elderly patients with different histological subgroups (26). Conversely, for younger patients, resected lobectomy and lobectomy are preferred. Cao's meta-analysis suggests that

"intentional selection" and "compromise" may influence the difference in prognosis between the two surgical approaches (27). Lungectomy can be chosen for young patients, and for older patients, resection should be more appropriate.

In addition, patients undergoing complete LN staging are considered to have a good clinical status, so lobectomy is planned. However, patients with poor medical conditions are more likely to be scheduled for a segmentectomy, which may result in laminectomy with comparable OS and LCSS and lobectomy in both.

Therefore, unbalanced baseline characteristics may result in false positive results. Since the number of LNs examined depends on the pathology report, further RCTs need to focus on the effect of the regional LN range on the difference in prognosis between the two surgical treatments (28).

In addition, due to the retrospective nature of all included studies, imbalances in baseline demographic and clinical characteristics, prejudice still exists, which may affect the comparison of outcomes of interest. Therefore, it shows that better design studies have stronger statistical power, which is essential for comparing the survival outcomes of segmentectomy and lobectomy.

\section{Conclusions}

In conclusion, our study showed that segmental resection and lobectomy resulted in similar local recurrence-free survival or overall survival in patients with clinical stage I NSCLC. From a survival perspective, further randomized controlled 
trials will enter "personalized treatment," which will benefit patients from subtypes, which can be instructive for driving treatment decisions while accepting acceptable adverse events.

\section{Abbreviations}

non-small-cell lung cancer $\quad$ NSCLC

Lung cancer-specific survival LCSS

overall survival OS

low-dose helical computed tomography LDCT

high- resolution computed tomography $\quad$ HRCT

Kaplan-Meier $\quad \mathrm{K}-\mathrm{M}$

Surveillance, Epidemiology and End Results SEER

\section{Declarations}

\section{Conflict of Interest}

The authors declare there is no conflict of interest existed in this study.

\section{Declarations}

Ethics approval and consent to participate: Not applicable.

Consent for publication: Not applicable.

Availability of data and material: The datasets generated and analyzed during the current study are available from the corresponding author on reasonable request.

Competing interests: There is no competing interest.

Funding: No funding was received for this study.

Authors' contributions: Jian Feng and Yan-Yue Han have made substantial contributions to conception and design of the study, written the manuscript; Yue Wang and Xiu-Yu Wu earched literature, extracted data from the collected literature and analyzed the data; Jian Feng revised the manuscript; All authors approved the final version of the manuscript.

Acknowledgements: None.

\section{References}

1. Aberle DR, Adams AM, Berg CD, et al. Reduced lung-cancer mortality with low-dose computed tomographic screening. N Engl J Med. 2011; 365(5):395-409. 《

2. Landreneau R J, Normolle D P, Christie N A, et al. Recurrence and survival outcomes after anatomic segmentectomy versus lobectomy for clinical stage I non-small-cell lung cancer: a propensity-matched analysis.[J]. Journal of Clinical Oncology, 2014, 32(23):2449-2455. 
3. Ginsberg R J , Rubinstein L V . Randomized trial of lobectomy versus limited resection for T1 N0 non-small cell lung cancer. Lung Cancer Study Group[J]. The Annals of Thoracic Surgery, 1995, 60(3):615-22; discussion 622-3.

4. Whitson B A , Groth S S , Andrade R S , et al. Survival After Lobectomy Versus Segmentectomy for Stage I Non-Small Cell Lung Cancer: A Population-Based Analysis[J]. Annals of Thoracic Surgery, 2011, 92(6):1943-1950.

5. Mery C M , Pappas A N , Bueno R, et al. Similar Long-term Survival of Elderly Patients With Non-small Cell Lung Cancer Treated With Lobectomy or Wedge Resection Within the Surveillance, Epidemiology, and End Results Database[J]. Chest, 2005, 128(1):237-245.

6. Zhong C, Fang W, Mao T, et al. Comparison of thoracoscopic segmentectomy and thoracoscopic lobectomy for small-sized stage IA lung cancer.[J]. Annals of Thoracic Surgery, 2012, 94(2):362-367.

7. Wisnivesky J P, Henschke C I , Swanson S, et al. Limited Resection for the Treatment of Patients With Stage IA Lung Cancer[J]. Annals of Surgery, 2010, 251(3):550-554.

8. Sugi K, Kobayashi S , Sudou M , et al. Long-term prognosis of video-assisted limited surgery for early lung cancer[J]. European journal of cardio-thoracic surgery: official journal of the European Association for Cardio-thoracic Surgery, 2009, 37(2):456-460.

9. Tsutani Y, Miyata $\mathrm{Y}$, Nakayama $\mathrm{H}$, et al. Oncologic outcomes of segmentectomy compared with lobectomy for clinical stage IA lung adenocarcinoma: propensity score-matched analysis in a multicenter study.[J]. Journal of Thoracic \& Cardiovascular Surgery, 2013, 146(2):358-364.

10. Jensik R J , Faber L P , Milloy F J , et al. Segmental resection for lung cancer. A fifteen-year experience[J]. Journal of Thoracic and Cardiovascular Surgery, 1973, 66(4):563-572.

11. Sihoe A D, Van S P. Non-small cell lung cancer: when to offer sublobar resection.[J]. Lung Cancer, 2014, 86(2):115120.

12. Tierney, J.F.; Stewart, L.A.; Ghersi, D.; Burdett, S.; Sydes, M.R. Practical methods for incorporating summary time-toevent data into meta-analysis. Trials, 2007. 8, 16 DOI: 10.1186/1745-6215-8-16.

13. Higgins J, et al. Quantifying heterogeneity in a meta-analysis. Statistics in Medicine 21, 1539-1558 (2002).

14. Higgins J, et al. Measuring inconsistency in meta-analyses. BMJ 327, 557 (2003).

15. Fiorelli A , Caronia F P , Daddi, Niccolò, et al. Sublobar resection versus lobectomy for stage I non-small cell lung cancer: an appropriate choice in elderly patients?[J]. Surgery Today, 2016, 46(12):1370-1382.

16. Kodama K, Higashiyama M, Okami J, et al. Oncologic Outcomes of Segmentectomy Versus Lobectomy for Clinical T1a NO M0 Non-Small Cell Lung Cancer[J]. Annals of Thoracic Surgery, 2016, 101(2):504-511.

17. Roman M , Labbouz S , Valtzoglou V, et al. Lobectomy vs. segmentectomy. A propensity score matched comparison of outcomes[J]. European Journal of Surgical Oncology (EJSO), 2018.

18. Moon M H, Moon Y K, Moon S W. Segmentectomy versus lobectomy in early non-small cell lung cancer of 2 ? $\mathrm{cm}$ or less in size: A population-based study[J]. Respirology, 2018.

19. Qu X, Wang K, Zhang T, et al. Long-term outcomes of stage I NSCLC ( $\leq 3 \mathrm{~cm})$ patients following segmentectomy are equivalent to lobectomy under analogous extent of lymph node removal: a PSM based analysis.[J]. Journal of Thoracic Disease, 2017, 9(11):4561.

20. Baue A E. Evarts A. Graham and the First Pneumonectomy[J]. Jama the Journal of the American Medical Association, 1984, 251(2):261-264.

21. Ellis H. The first pneumonectomies for lung cancer[J]. Journal of Perioperative Practice, 2008, 18(3):130.

22. Churchill E D , Sweet R H , Soutter L , et al. The surgical management of carcinoma of the lung; a study of the cases treated at the Massachusetts General Hospital from 1930 to 1950[J]. Journal of Thoracic Surgery, 1950, 20(3):349. 
23. Nakamura K, Saji H, Nakajima R, et al. A phase III randomized trial of lobectomy versus limited resection for smallsized peripheral non-small cell lung cancer (JCOG0802/WJOG4607L)[J]. Japanese Journal of Clinical Oncology, 2010, 40(3):271-274.

24. Aokage K, Saji H, Suzuki K, et al. A non-randomized confirmatory trial of segmentectomy for clinical T1N0 lung cancer with dominant ground glass opacity based on thin-section computed tomography (JCOG1211)[J]. General Thoracic and Cardiovascular Surgery, 2017, 65(5):267-272.

25. Smith C B , Swanson S J , Mhango G, et al. Survival after segmentectomy and wedge resection in stage I non-smallcell lung cancer.[J]. Journal of Thoracic Oncology Official Publication of the International Association for the Study of Lung Cancer, 2013, 8(1):73-78.

26. Veluswamy R R, Ezer N, Mhango G , et al. Limited Resection Versus Lobectomy for Older Patients With Early-Stage Lung Cancer: Impact of Histology[J]. Journal of Clinical Oncology, 2015:JC0.2014.60.6624.

27. Cao C, Chandrakumar D, Gupta S, et al. Could less $₫$ be more?-A systematic review and meta-analysis of $\otimes$ sublobar resections versus lobectomy for non-small cell『lung cancer according to patient selection. Lung Cancer 2015;89:121-32. 》

28. Osarogiagbon R U , Ogbata O , Yu X . Number of Lymph Nodes Associated With Maximal Reduction of Long-Term Mortality Risk in Pathologic Node-Negative Non-Small Cell Lung Cancer[J]. The Annals of Thoracic Surgery, 2014, 97(2):385-393.

\section{Tables}

Table 1 Characteristics of the eligible studies

\begin{tabular}{|l|l|l|l|l|l|l|l|l|}
\hline \multirow{2}{*}{$\begin{array}{l}\text { Study } \\
\text { year }\end{array}$} & No. of patients & Age(Mean) & \multicolumn{2}{l|}{ Sex(Male) } & \multicolumn{2}{l|}{ Tumor size(Mean) } \\
\cline { 2 - 9 } & Segmentectomy & Lobectomy & Segmentectomy & Lobectomy & Segmentectomy & Lobectomy & Segmentectomy & Lobectomy \\
\hline $\begin{array}{l}\text { Landreneau } \\
\text { R-J 2014 }\end{array}$ & 312 & 312 & 68.5 & 68.4 & 139 & 144 & 2.2 & 2.2 \\
\hline $\begin{array}{l}\text { Alfonso } \\
\text { Fiorelli } \\
2016\end{array}$ & 35 & 138 & $/$ & $/$ & $/$ & $/$ & $/$ & $/$ \\
\hline $\begin{array}{l}\text { Whitson } \\
\text { BA 2011 }\end{array}$ & 581 & 13892 & $/$ & $/$ & 320 & 6974 & $/$ & $/$ \\
\hline $\begin{array}{l}\text { Ken } \\
\text { Kodama } \\
\text { 2015 }\end{array}$ & 69 & 69 & $/$ & $/$ & 33 & 32 & $/$ & $/$ \\
\hline $\begin{array}{l}\text { M. Roman } \\
\text { 2018 }\end{array}$ & 64 & 64 & $/$ & & & & & \\
\hline $\begin{array}{l}\text { Moon M-H } \\
2018\end{array}$ & 809 & 809 & 67.8 & 67.9 & 278 & $/$ & 32.4 & 24.6 \\
\hline $\begin{array}{l}\text { Xiao Qu } \\
\text { 2017 }\end{array}$ & 1146 & 1146 & $/$ & $/$ & 452 & 449 & $/$ & 14.4 \\
\hline
\end{tabular}

\section{Figures}




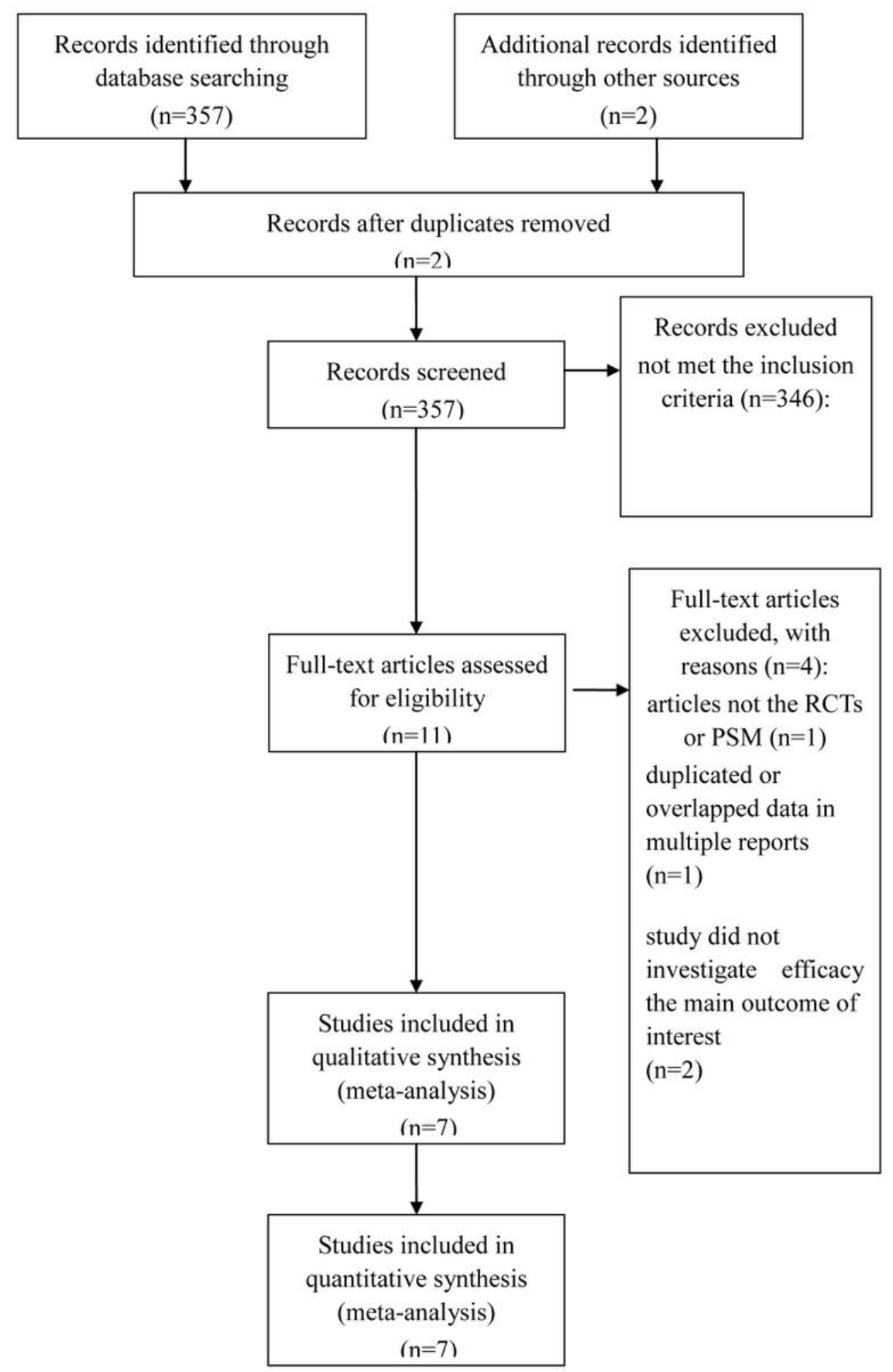

Figure 1

PRISMA flow chart of selection process to identify studies eligible for pooling

\begin{tabular}{|c|c|c|c|c|c|c|c|c|}
\hline Study or Subgroup & log[Odds Ratio] & SE & Weight & $\begin{array}{l}\text { Odds Ratio } \\
\text { IV, Random, } 95 \% \mathrm{CI}\end{array}$ & \multicolumn{4}{|c|}{$\begin{array}{c}\text { Odds Ratio } \\
\text { IV, Random, } 95 \% \mathrm{Cl}\end{array}$} \\
\hline Alfonso Fiorelli 2016 & -0.9163 & 0.5356 & $14.7 \%$ & $0.40[0.14,1.14]$ & & & & \\
\hline Moon M-H 2018 & 0.1169 & 0.1366 & $27.9 \%$ & $1.12[0.86,1.47]$ & & & & \\
\hline Xiao Qu 2017 & 0.0383 & 0.0959 & $28.8 \%$ & $1.04[0.86,1.25]$ & & & & \\
\hline Total $(95 \% \mathrm{Cl})$ & & & $100.0 \%$ & $0.72[0.41,1.26]$ & & & & \\
\hline
\end{tabular}

Figure 2 
Pooled analysis of LCSS comparing lobectomy versus segmentectomy

\begin{tabular}{|c|c|c|c|c|c|c|c|c|}
\hline Study or Subgroup & log[Odds Ratio] & SE & Weight & $\begin{array}{l}\text { Odds Ratio } \\
\text { IV, Random, } 95 \% \mathrm{CI}\end{array}$ & & $\begin{array}{r}\text { Odds F } \\
\text { IV, Random }\end{array}$ & $\begin{array}{l}\text { Ratio } \\
\mathrm{m}, 95 \% \mathrm{Cl}\end{array}$ & \\
\hline Alfonso Fiorelli 2016 & -0.3857 & 0.3846 & $11.1 \%$ & $0.68[0.32,1.44]$ & & & & \\
\hline Ken Kodama 2015 & 0.5306 & 0.978 & $3.0 \%$ & $1.70[0.25,11.56]$ & & & & \\
\hline Landreneau R-J 2014 & -0.0943 & 0.1195 & $19.8 \%$ & $0.91[0.72,1.15]$ & & & & \\
\hline M. Roman 2018 & -0.6349 & 0.8509 & $3.8 \%$ & $0.53[0.10,2.81]$ & & & & \\
\hline Moon M-H 2018 & 0.1781 & 0.0945 & $20.5 \%$ & $1.19[0.99,1.44]$ & & & 6 & \\
\hline Whitson BA 2011 & -0.6539 & 0.0738 & $20.9 \%$ & $0.52[0.45,0.60]$ & & $\rightarrow-$ & & \\
\hline Xiao Qu 2017 & 0.0779 & 0.0729 & $20.9 \%$ & $1.08[0.94,1.25]$ & & & & \\
\hline Total $(95 \% \mathrm{CI})$ & & & $100.0 \%$ & $0.86[0.60,1.23]$ & & & & \\
\hline \multicolumn{5}{|c|}{$\begin{array}{l}\text { Heterogeneity: } \text { Tau }^{2}=0.16 ; \mathrm{Chi}^{2}=69.65, \mathrm{df}=6(\mathrm{P}<0.00001) ; \mathrm{I}^{2}=91 \% \\
\text { Test for overall effect: } Z=0.84(P=0.40)\end{array}$} & $\begin{array}{ll} & \\
0.1 & 0.2\end{array}$ & $\begin{array}{c}0.5 \\
\text { Lobectomy }\end{array}$ & ${ }_{\text {Segmentectomy }}^{2}$ & $\begin{array}{l}1 \\
5 \\
y\end{array}$ \\
\hline
\end{tabular}

Figure 3

Pooled analysis of OS comparing lobectomy versus segmentectomy

\section{Supplementary Files}

This is a list of supplementary files associated with this preprint. Click to download.

- PRISMA2009checklist.doc 